\title{
PERANCANGAN PURWARUPA KARTU BELAJAR BERTEKSTUR SEBAGAI MEDIA UNTUK MENGENALKAN HURUF PADA ANAK USIA DINI
}

\author{
Yanuar Rahman ${ }^{1}$, Rizki Yantami Arumsari², Devi Arifiani Azhar ${ }^{3}$ \\ 1,2Desain Komunikasi Visual, Fakultas Industri Kreatif, Universitas Telkom \\ Terusan Buah Batu Bandung 40257 \\ ${ }^{3}$ Komunitas Familia Kreativa, Bandung 40287 \\ email: ${ }^{1}$ vidiyan@gmail.com, ${ }^{2}$ rizkiyantami@gmail.com, ${ }^{3}$ deviazhar@gmail.com
}

\begin{abstract}
Abstrak: Masa keemasan (golden ages) bagi seorang anak merupakan masa pertumbuhan dan perkembangan yang merupakan periode kritis dan berdampak pada perkembangan aspek kognitif, afektif dan psikomotor anak. Pada masa ini orang tua kerap menstimulus berbagai dimensi perkembangan anak dengan beragam cara. Salah satunya adalah ranah kognitif yang sering distimulus dengan banyak jalan, misalnya dengan menggunakan kartu sebagai media belajar. Pada saat ini, telah begitu banyak varian kartu belajar yang dapat ditemui, namun didominasi oleh kartu yang ditujukan untuk dicerap oleh indera pengelihatan. Padahal begitu banyak potensi yang bisa dioptimalkan oleh kartu-kartu jenis ini, misalnya kartu belajar yang bisa dicerap oleh indera peraba, selain pengelihatan. Melalui pengamatan, studi pustaka, wawancara dan proses perancangan, penelitian ini menghasilkan sebuah produk purwarupa yang mengeksplorasi bentuk-bentuk baru dari kartu belajar, terutama yang dapat digunakan dengan cara dilihat dan diraba. Purwarupa kartu ini bisa dimanfaatkan bagi anak-anak dalam membantu cara belajar mereka, lebih jauh lagi kartu ini dapat dioptimalkan sebagai alat bantu oleh anak-anak berkebutuhan khusus.
\end{abstract}

Kata kunci: kartu, belajar, tekstur, indera peraba, anak-anak

Abstract: The golden age for a child is a period of growth and development which is a critical period and has an impact on his/her development of cognitive, affective and psychomotor aspects. At this time parents often stimulate various dimensions of child development in various methods. One of them is the cognitive realm which is often stimulated in many techniques, for example by using cards as learning media. At this time, there are so many variants of learning cards that can be found, however those are dominated by cards intended to be perceived by the sense of sight. In fact, numerous potentials can be optimized by these types of cards, for example learning cards that can be perceived by the sense of touch, in addition to vision. Through observation, literature study, interview and design process, this research produces a prototype product that explores new forms of learning cards, especially those that can be utilized by being seen and touched. The prototype of this card can be used by children in helping their learning, furthermore this card can be optimized as a tool for children with special needs.

Keywords: cards, learning, texture, sense of touch, children 


\section{PENDAHULUAN}

Usia dini mutlak menjadi masa-masa berharga bagi seorang anak dan orang tuanya untuk bisa memperkuat bonding yang merupakan dasar pembentukan karakter anak, baik dalam ranah kognitif, afektif maupun psikomotor. Pada masa-masa ini orangtua biasanya menanamkan banyak hal untuk menstimulus berbagai indera buah hatinya, karena sejak dilahirkan hingga usia tujuh tahun anak-anak menjalani masa pertumbuhan dan perkembangan yang sangat menentukan bagi masa depannya. Masa ini juga merupakan periode kritis yang sangat memengaruhi tahap pertumbuhan dan perkembangan anak selanjutnya (Kertamuda, 2015), di mana otak anak mengalami peningkatan perkembangan paling cepat.

Pada masa keemasan ini orang tua kerap menginginkan buah hatinya untuk bisa belajar banyak hal, mulai dari aktivitas sederhana, seperti motorik kasar dan halus hingga aktifitas kognitif yang merangsang perkembangan otaknya. Memasuki usia dua atau tiga tahun orang tua sudah dapat menstimulus anak dengan berbagai kegiatan salah satunya adalah mempelajari benda-benda di sekitarnya dengan bantuan artefak asli maupun gambar-gambar yang mewakili, melalui media tercetak ataupun digital.

Perkembangan masa kanak-kanak meliputi beragam dimensi mulai dari kemampuan berbahasa, kreatifitas, kesadaran sosial, emosional dan intelegensi, kesemuanya ini berjalan dengan cepat dan progresif. Dalam perkembangan ini, otak anak lebih terbuka untuk dapat diperkaya dengan cara belajar, pada masa ini juga otak akan lebih peka terhadap lingkungan. Oleh karena itu anak harus mendapat perhatian yang serius pada awal kehidupannya. Jika hal ini terabaikan maka berpotensi dapat memperlambat perkembangan anak yang dalam skala makro hal ini dapat berpengaruh pada tingkat kecerdasan bangsa (Apriastuti, 2013). Kemampuan yang cukup penting untuk distimulasi pada masa kanak-kanak adalah kemampuan berkomunikasi, seperti yang diungkapkan Vortuna, Ratiyah 
dan Syafdaningsih (2018) bahwa untuk berkomunikasi anak perlu distimulasi dengan dikenalkan huruf-huruf berupa simbol tertulis; dan keterkaitan antara bentuk serta bunyinya, sehingga anak dapat membedakan setiap huruf dan memaknainya. Banyak cara dan metode yang dapat digunakan untuk mengenalkan huruf kepada anak-anak, misalnya menggunakan tutup botol hias, buku alfabet, permainan ular tangga, permainan kantong ajaib, boneka jari dan lain sebagainya (Handayani dan Nurhafizah, 2019).

Salah satu perangkat bantu yang kerap digunakan orang tua untuk mengajarkan anak-anaknya dalam mengenal huruf adalah dengan menggunakan kartu belajar. Meski dinamakan kartu belajar, namun dalam penggunaannya kartu ini lebih dominan digunakan secara bermain, karena Puspitasari (2015) menyatakan bahwa bermain merupakan salah satu prinsip dalam pembelajaran anak usia dini. Bermain merupakan pekerjaan bagi anak, apa yang dilakukan anak semuanya adalah bermain. Hal ini dikarenakan bermain adalah sesuatu yang menyenangkan, tanpa paksaaan, serta tindakan bebas bagi anak untuk menentukan pilihan.

Kartu belajar yang banyak beredar dan dimanfaatkan di masyarakat sebagai alat bantu belajar untuk anak-anak saat ini berupa kartu belajar yang memanfaatkan visualisasi yang dapat dicerap oleh indera pengelihatan. Sejatinya terdapat potensi berbeda yang dapat dikembangkan dari kartu sejenis, misalnya varian kartu yang dapat dicerap oleh indera pengelihatan dan peraba, sehingga target audiens yakni anak-anak ketika menggunakan kartu ini dapat merespon lebih eksploratif dengan cara meraba permukaan kartu tersebut. Menurut Rahmadani, Suryana dan Hartati (2019), salah satu variasi kartu belajar yaitu sandpaper letter yang kerap digunakan dalam metode montessori. Kartu yang menggunakan bahan menyerupai amplas halus ini bertujuan sebagai latihan untuk membangun mekanisme otot yang diperlukan untuk kemampuan memegang dan menggunakan alat tulis, lalu jari anak yang telah terlatih melalui kegiatan meraba 
bentuk-bentuk huruf dapat menjadi pelengkap dalam wawasan visual anak tentang huruf.

Sudjana dan Rivai dalam Apriastuti (2013) juga memperkuat bahwa proses belajar siswa dapat dioptimalkan dengan menggunakan media pembelajaran yang akhirnya diharapkan dapat memperbaiki kualitas hasil belajar yang dicapai siswa tersebut. Kartu belajar yang dapat diraba ini memiliki tekstur yang diharapkan dapat membantu proses belajar agar anak tidak sekedar mengetahui konten yang dikandung kartu belajar tersebut, tapi juga dapat memahaminya.

Selain untuk anak-anak usia dini, kartu belajar bertekstur ini juga diharapkan dapat bermanfaat dan digunakan secara optimal bagi anak-anak berkebutuhan khusus, karena secara kuantitas alat bantu media pembelajaran bagi anak berkebutuhan khusus masih dirasakan kurang. Oleh karena itu sangat diharapkan media pembelajaran dapat diupayakan lebih banyak dan lebih baik lagi agar dapat meningkatkan mutu pendidikan (Mais, 2018).

Berdasarkan paparan tersebut, penelitian ini bertujuan untuk merancang purwarupa kartu belajar bertekstur dalam beberapa teknik yang bisa dimanfaatkan oleh anak-anak untuk mengenal huruf yang juga dapat menstimulus beragam panca indera dan mengoptimalkan proses belajar.

\section{METODE PENELITIAN}

Sampel visual pada penelitian ini adalah beberapa seri kartu mengenal huruf yang bertuliskan/ bergambar aneka huruf abjad " $A$ " sampai " $Z$ " dalam berbagai varian untuk anak usia dini. Beberapa contoh yang diambil diantaranya hasil karya dari produsen kartu "Iqra Balita", "Educa Studio", dan "Flashcard Jogja". Soewardikoen (2013:16) menekanan bahwa peneliti harus melihat gambar secara seksama agar bisa 'dibaca' dan didefinisikan menjadi sebuah persepsi yang dapat dirangkai menjadi sebuah informasi. 


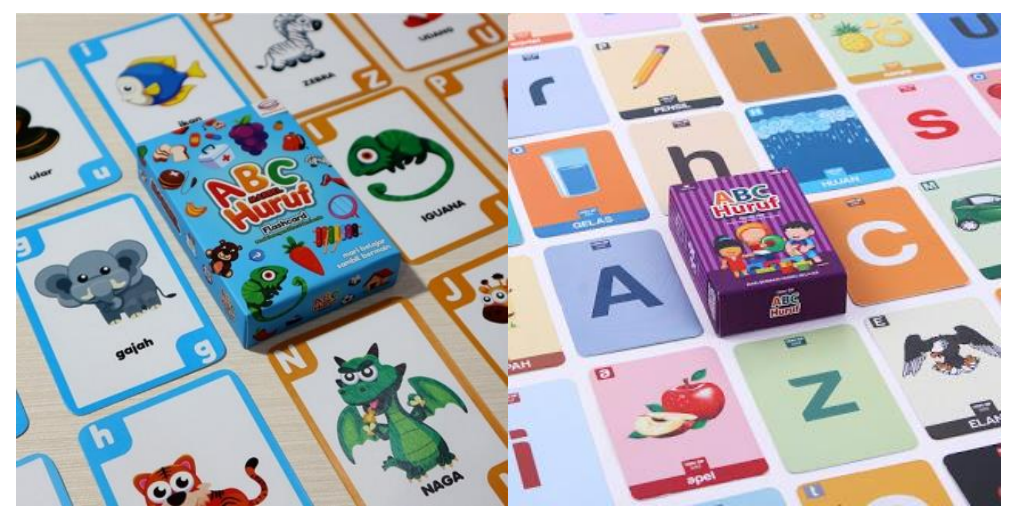

Gambar 1. Sample visual kartu belajar

Sumber: https://cf.shopee.co.id/file/10d41e639e74354bd2423f60d7eebed1

Studi pustaka untuk memperkuat penelitian ini akan dikumpulkan melalui berbagai sumber buku maupun e-book yang kontekstual, guna memperoleh berbagai landasan pemikiran dan opini pakar dalam bidang desain, pendidikan anak dan psikologi anak sesuai dengan tujuan penelitian. Beberapa penelitian yang dijadikan rujukan antara lain mengenai relasi antara tingkat pendidikan dan pola asuh orang tua terhadap perkembangan anak usia 4-6 tahun; bagaimana cara membentuk karakter emas sejak anak berusia dini; media pembelajaran anak berkebutuhan khusus; dan beberapa rujukan lain yang relevan. Djiwandono (2015:27) juga mengungkapkan bahwa teori-teori ini akan digunakan untuk menganalisis data-data yang didapatkan di lapangan, juga untuk memberikan sudut pertimbangan lain yang berbeda agar cara pandang penelitian dapat lebih luas dan obyektif.

Wawancara secara langsung dilakukan kepada beberapa narasumber untuk menggali data primer maupun pendapat pembanding, yakni psikolog anak Ibu Birlanti Novitasari, M. Psi, dan ahli pendidikan anak Ibu Badriyah Puspawardani, S. Sos selaku pendiri Sanggar Raiya di Bandung. Kedua narasumber ini berpendapat senada bahwa sejak dini anak-anak sudah bisa distimulus berbagai inderanya, juga area sensori motoriknya. Cara menstimulusnya bisa dilakukan dengan bergam cara misalnya menggunakan media bermain seperti playdough, slime, pasir 
kinetik, dan media-media lain yang bisa merangsang beberapa indera seperti penglihatan dan peraba secara berkesinambungan dan padu.

Setelah melakukan studi pustaka dan wawancara, menurut Pressman (2010) langkah selanjutnya adalah perancangan yang merupakan langkah pertama dalam fase pengembangan rekayasa produk atau sistem. Perancangan itu adalah proses penerapan berbagai teknik dan prinsip yang bertujuan untuk mendefinisikan sebuah peralatan, satu proses atau satu sistem secara detail yang membolehkan dilakukan realisasi fisik.

Perancangan akan dilakukan melalui beberapa tahap dengan menggunakan berbagai bahan untuk mendapatkan desain kartu belajar terbaik dan paling sesuai untuk anak usia dini. Tahap pertama yakni praproduksi, dengan memilih alternatif bahan dasar dan material tekstur. Tahap kedua adalah produksi dengan mengombinasikan material-material yang sudah dipilih dan membentuknya ke dalam bentuk-bentuk huruf. Pada tahap ini dilakukan juga ujicoba guna mendapatkan respon. Tahap terakhir adalah praproduksi, yaitu mengevaluasi hasil kartu yang sudah dibuat, dan memberikan beberapa sudut pandang untuk dapat menjadikannya berguna bagi masyarakat luas.

Akhir dari proses ini adalah penarikan kesimpulan yang dilakukan dengan cara menyimpulkan dari satu atau beberapa fakta dengan melakukan perumusan konsep, proposisi, dan teoretis setelah hasil penelitian (Soewardikoen, 2013:50).

\section{HASIL DAN DISKUSI}

Perancangan akan menggunakan beberapa variasi material. Jika sandpaper letter terbuat dari kayu persegi dengan ketebalan $1 \mathrm{~cm}$ yang diimbuhi huruf berasal dari kertas ampelas (Rahmadani, Suryana, dan Hartati, 2019:58); maka perancangan kali ini menggunakan alternatif material lainnya seperti polypropylene corrugated sheet atau dikenal dengan merek dagang impraboard, pipe cleaner, kain flannel dan artpaper. Pemilihan material ini berdasarkan 
rekomendasi dari psikolog dan pemerhati anak, serta kemudahannya untuk didapatkan dengan harga terjangkau.

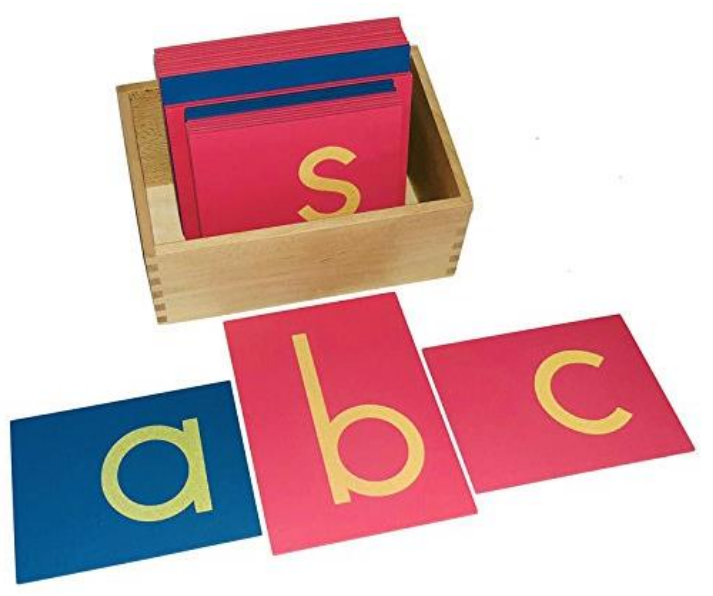

Gambar 2. Sandpaper letter

Sumber: https://www.amazon.com/Montessori-Lower-Case-Sandpaper-Letters/dp/B005JEA52A

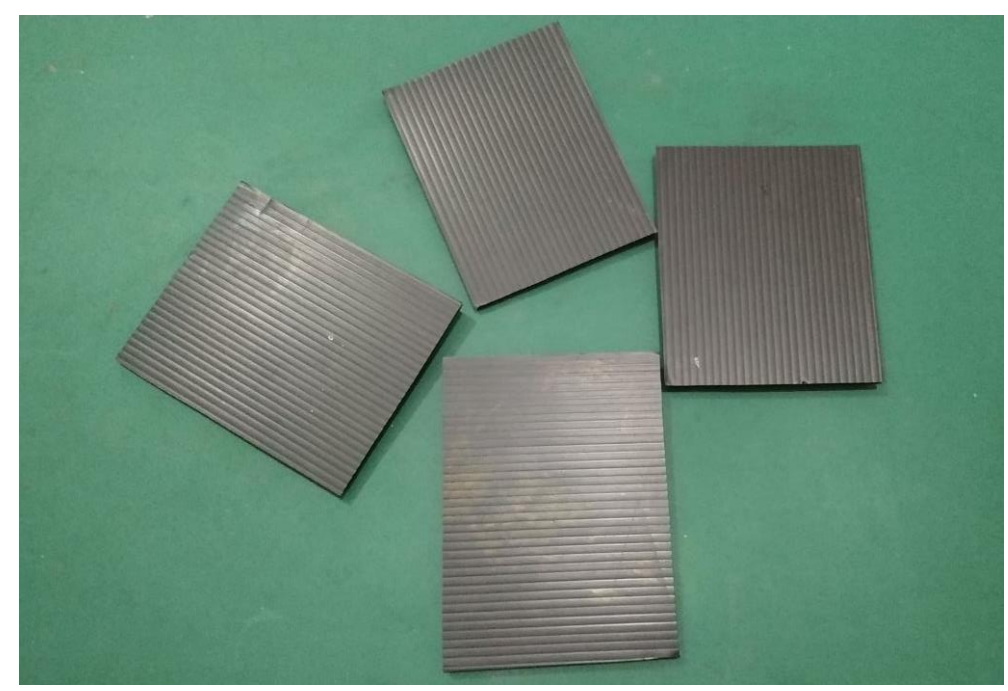

Gambar 3. Polypropylene corrugated sheet Sumber: Rahman, Arumsari dan Azhar, 2019 
Yanuar Rahman, Rizki Yantami Arumsari dan Devi Arifiani Azhar, PERANCANGAN PURWARUPA KARTU BELAJAR BERTEKSTUR SEBAGAI MEDIA UNTUK MENGENALKAN HURUF

PADA ANAK USIA DINI, 128 - 143

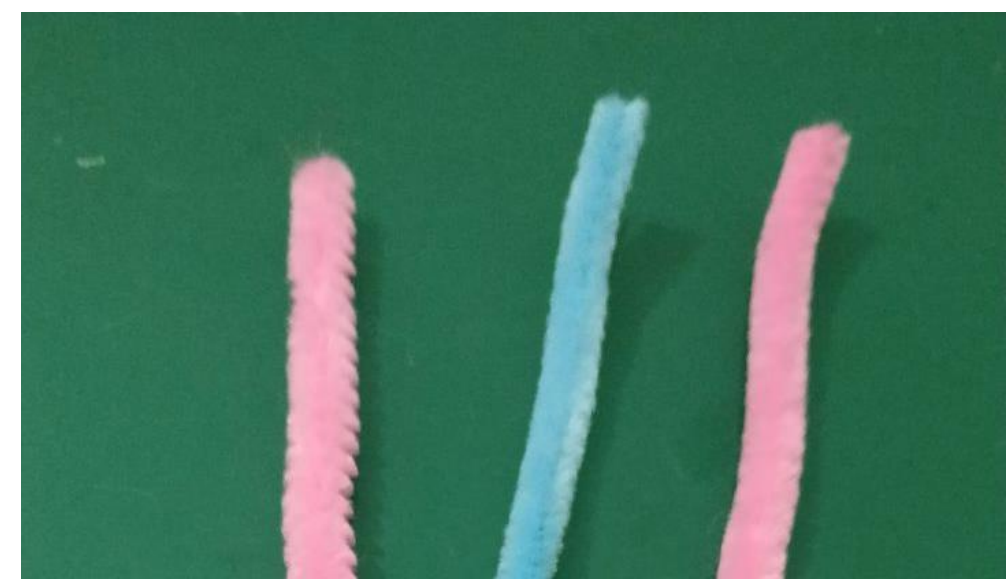

Gambar 4. Pipe cleaners

Sumber: Rahman, Arumsari dan Azhar, 2019

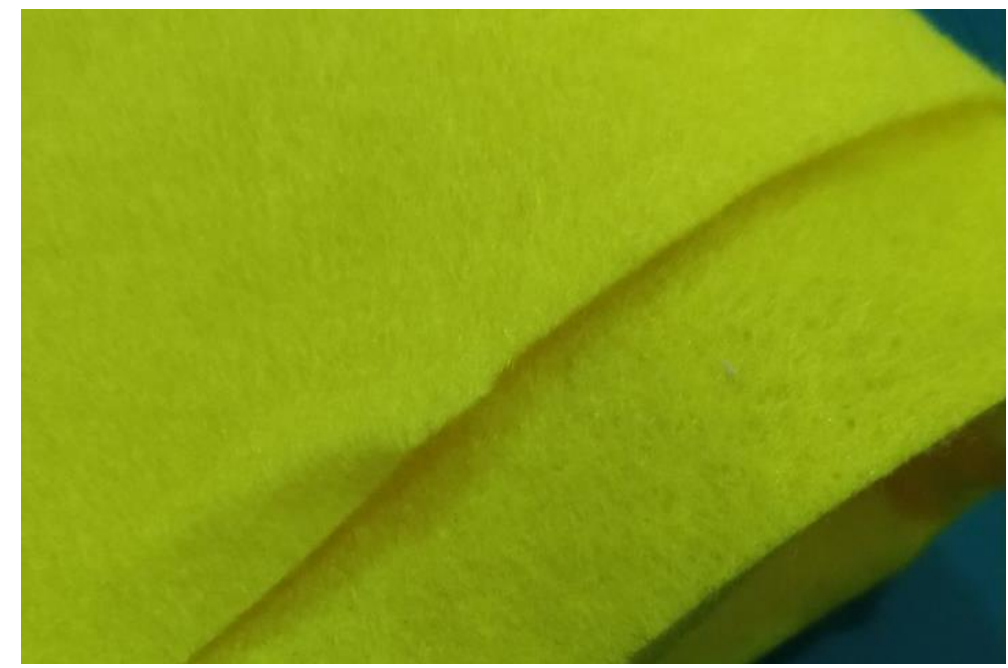

Gambar 5. Kain flannel

Sumber: Rahman, Arumsari dan Azhar, 2019

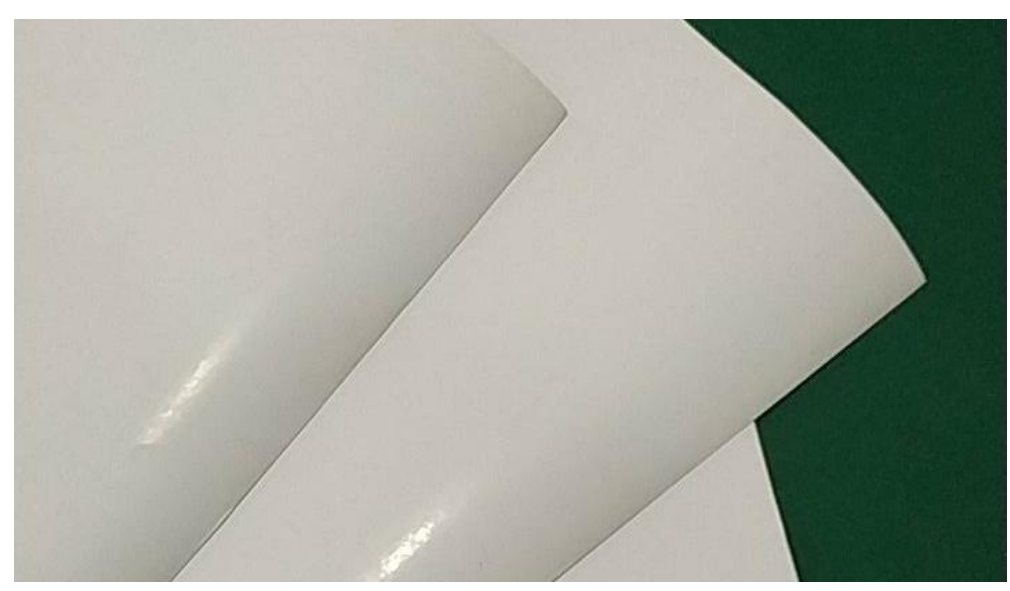

Gambar 6. Artpaper

Sumber: Rahman, Arumsari dan Azhar, 2019 
Purwarupa kartu pertama (Gambar 7 dan 8) dibuat menggunakan impraboard berukuran $8 \times 10 \mathrm{~cm}$. Huruf-huruf yang ditempel pada impraboard menggunakan pipe cleaner.

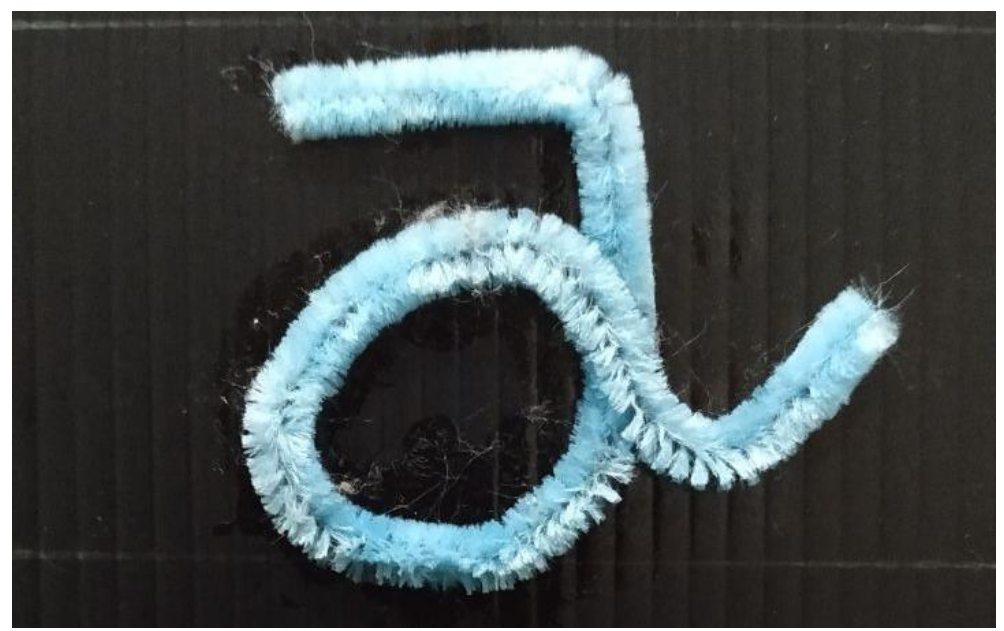

Gambar 7. Huruf "a" dibuat menggunakan pipecleaner Sumber: Rahman, Arumsari dan Azhar, 2019

Purwarupa ini menghasilkan huruf-huruf yang bisa diraba dengan tegas dan jelas karena bentuk timbulnya sangat tampak dan terasa. Kekurangannya adalah proses saat membuat desain huruf yang cenderung sulit dilakukan, sehingga menghasilkan huruf-huruf yang tampak tidak memiliki standar.

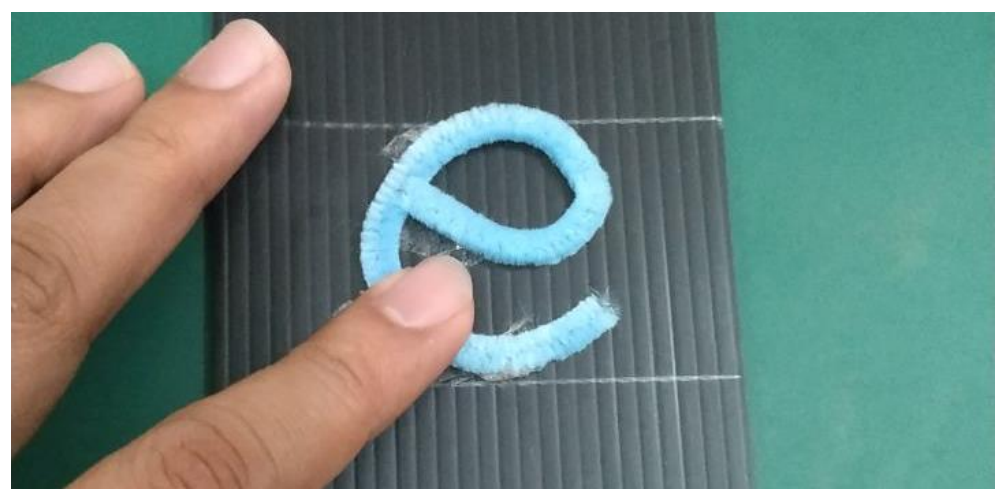

Gambar 8. Huruf "e" dibuat dengan pipe cleaner yang mudah diraba Sumber: Rahman, Arumsari dan Azhar, 2019 
Kekurangan berikutnya muncul dari aspek keamanan, karena pipe cleaner ini bahan pembentuk utamanya adalah kawat yang kemudian dilapisi kain menyerupai bulu, menyebabkan pada ujung-ujung huruf yang merupakan potongan kawat terasa cukup tajam, dan berpotensi melukai jemari anak jika menggunakannya dengan kurang hati-hati.

Purwarupa kedua (Gambar 9-11) dibuat menggunakan impraboard berukuran lebih besar dari purwarupa pertama, yakni 12 × $13 \mathrm{~cm}$ karena untuk satu kartu akan memuat dua huruf, yaitu huruf besar dan huruf kecil. Material huruf menggunakan kain flanel, serta desain jenis huruf yang digunakan mengambil dari salah satu rumpun huruf sans-serif yang berkarakter lembut dan cenderung komikal, yakni Sniglet. Purwarupa ini menghasilkan tekstur yang cukup baik, terasa lembut saat diraba dan cukup aman untuk digunakan oleh anak-anak.

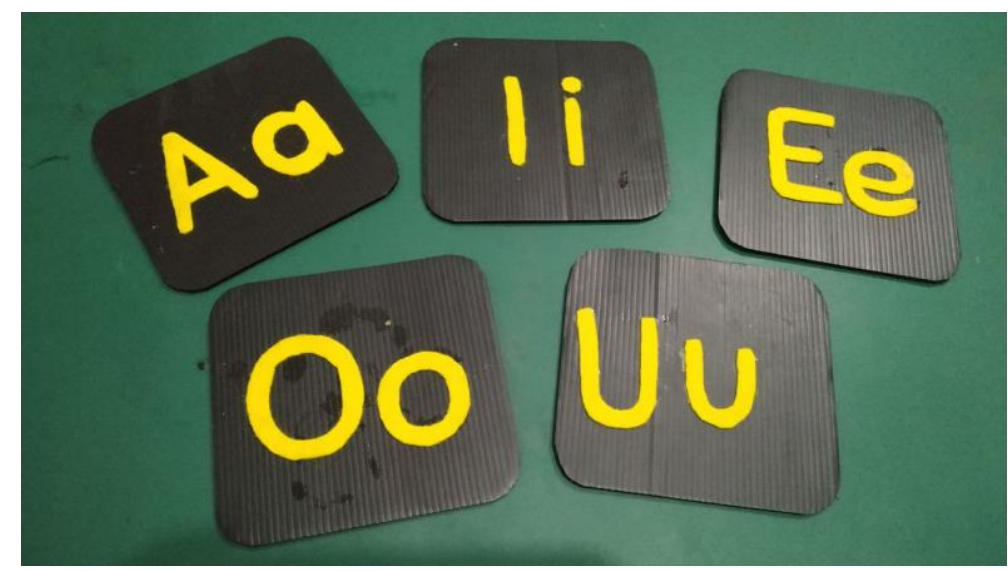

Gambar 9. Kartu huruf menggunakan kain flannel Sumber: Rahman, Arumsari dan Azhar, 2019

Kekurangannya kartu jenis ini terdapat dalam proses pembuatan hurufnya. Perlu tahapan yang cukup panjang untuk menghasilkan satu kartu yang terdiri dari dua jenis huruf, yakni huruf besar dan huruf kecil. 


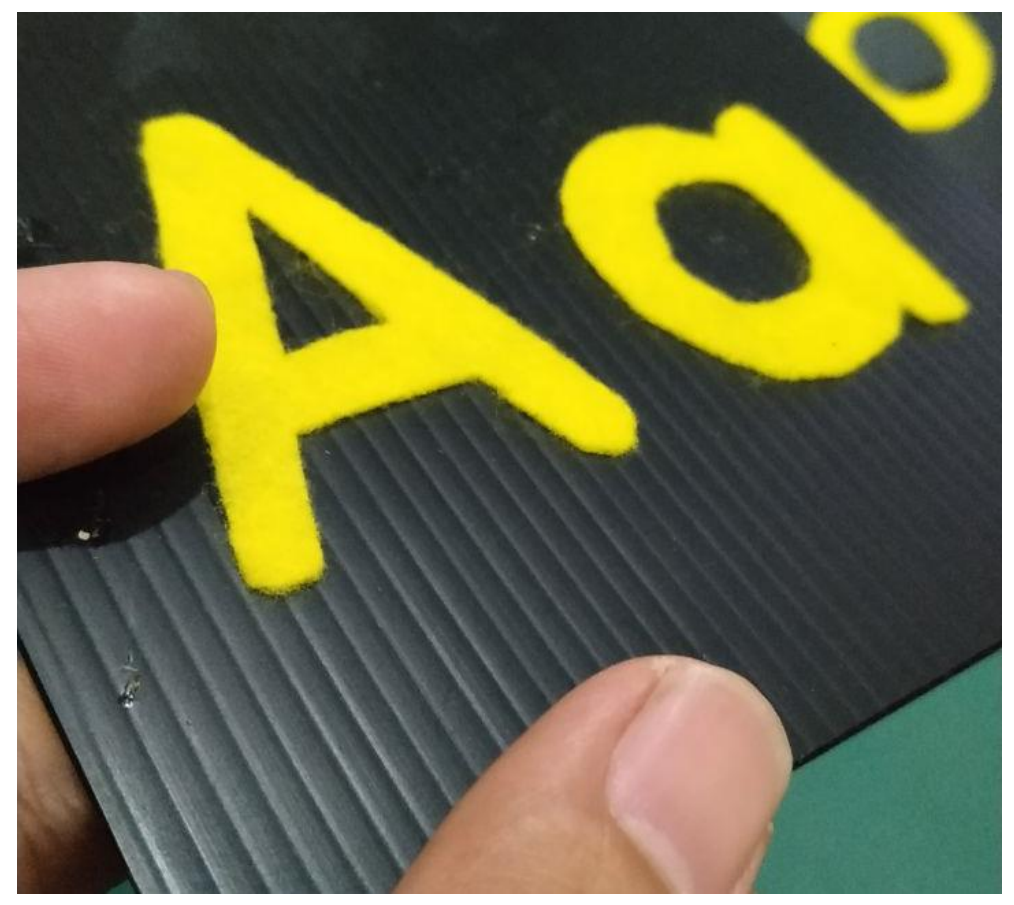

Gambar 10. Kartu yang dibuat dengan huruf flannel Sumber: Rahman, Arumsari dan Azhar, 2019

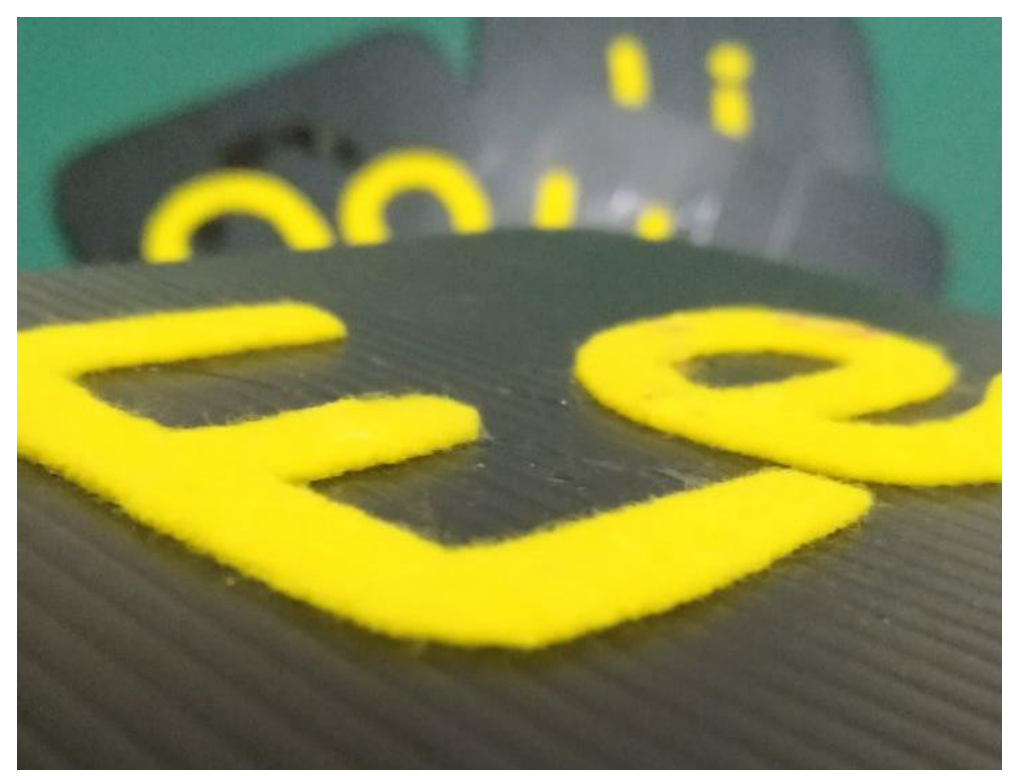

Gambar 11. Tekstur timbul yang mudah diraba Sumber: Rahman, Arumsari dan Azhar, 2019

Tahap awal adalah memilih huruf, kemudian dicetak di atas kertas hvs dengan ukuran yang cukup besar. Setelah itu dengan menggunakan karbon, huruf 
yang dicetak pada kertas hvs tersebut disalin diatas kain flannel. Kemudian kain flannel digunting mengikuti alur huruf dan hasilnya ditempelkan di impraboard.

Kartu model ketiga (Gambar 12-16) merupakan purwarupa yang paling panjang proses pembuatannya, namun hasilnya lebih aman dan bisa dibuat lebih massal. Pembuatan purwarupa ini menggunakan teknik desain melalui perangkat lunak pengolah grafis. Proses perancangannya membutuhkan ketelitian terutama saat pemilihan huruf dan pengaturan tata letak. Setelah proses tersebut selesai dilanjutkan dengan proses cetak dalam lembaran kertas yang berukuran besar yakni $32 \times 44 \mathrm{~cm}$, dalam satu lembar besar ini terdiri dari beberapa kartu.

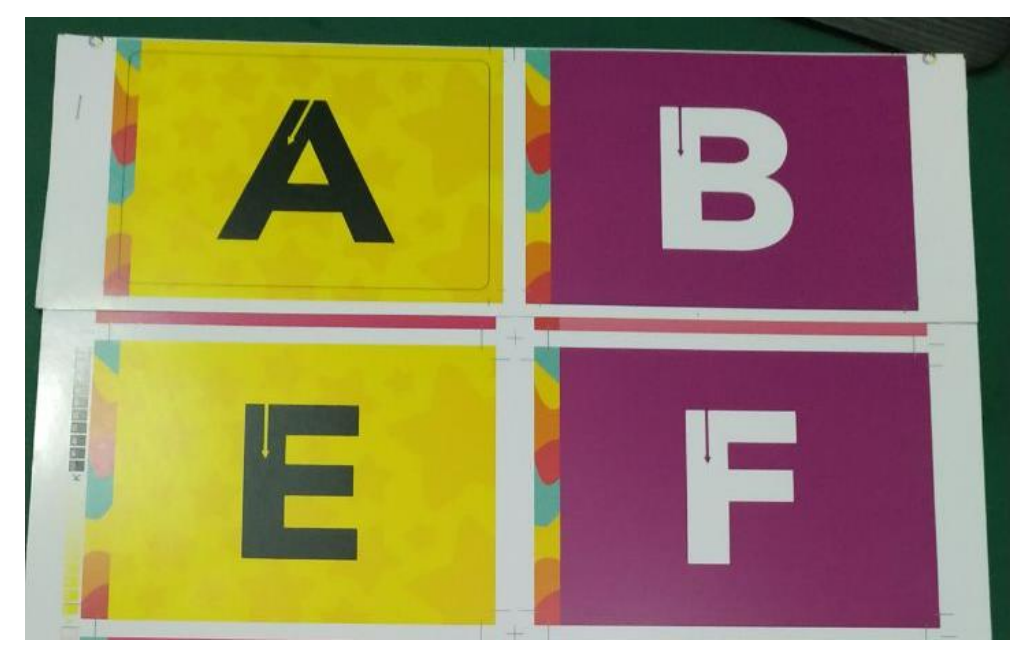

Gambar 12. Purwarupa kartu alternatif 3

Sumber: Rahman, Arumsari dan Azhar, 2019

Proses selanjutnya adalah melaminasi hasil cetakan tersebut dengan material laminasi yang bisa memunculkan tekstur kasar dan tidak rata. Teknik laminasi ini adalah laminasi glitter. Menurut hasil wawancara dengan ahli percetakan, teknik ini cukup sulit untuk membuat hasil yang standar karena sebagian prosesnya mengandalkan keterampilan tangan operator, sehingga meski semua huruf bisa dilaminasi dengan laminasi glitter, namun hasil tekstur glitternya tidak bisa sama rata. Meski demikian hasil cetakan dan laminasi yang diperoleh bisa dikatakan cukup representatif. 


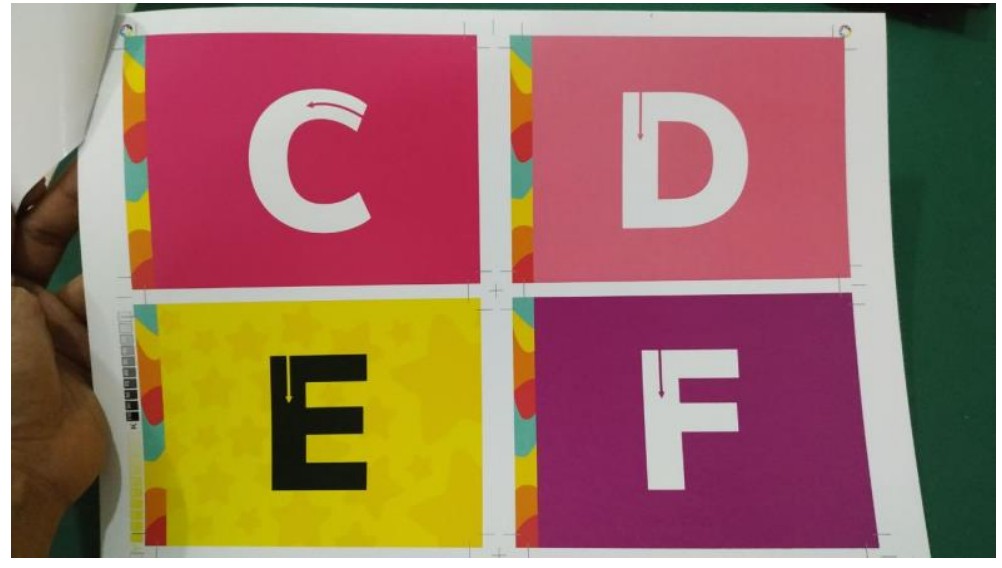

Gambar 13. Variasi huruf pada purwarupa kartu alternatif 3 Sumber: Rahman, Arumsari dan Azhar, 2019

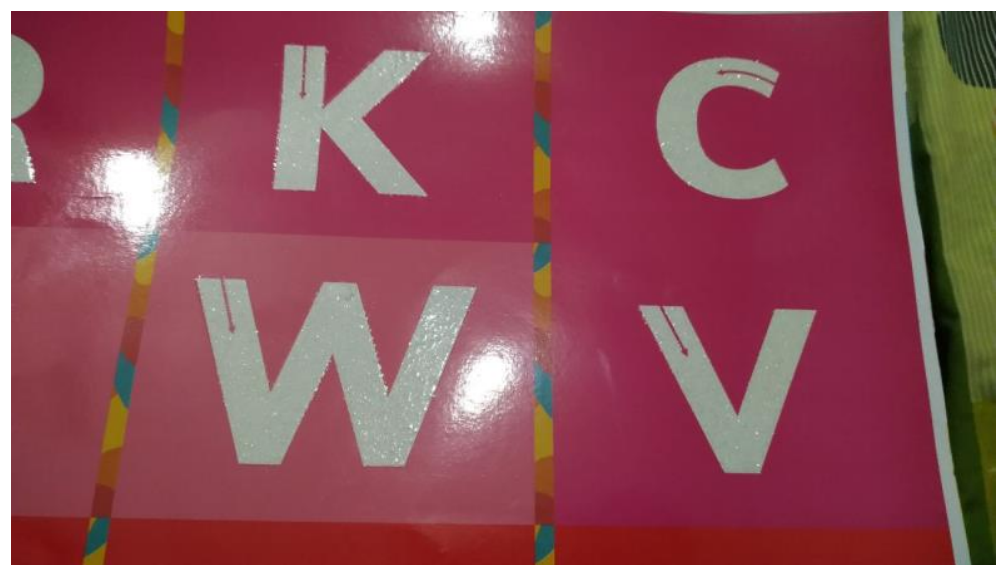

Gambar 14. Kartu setelah diproses laminasi glitter Sumber: Rahman, Arumsari dan Azhar, 2019

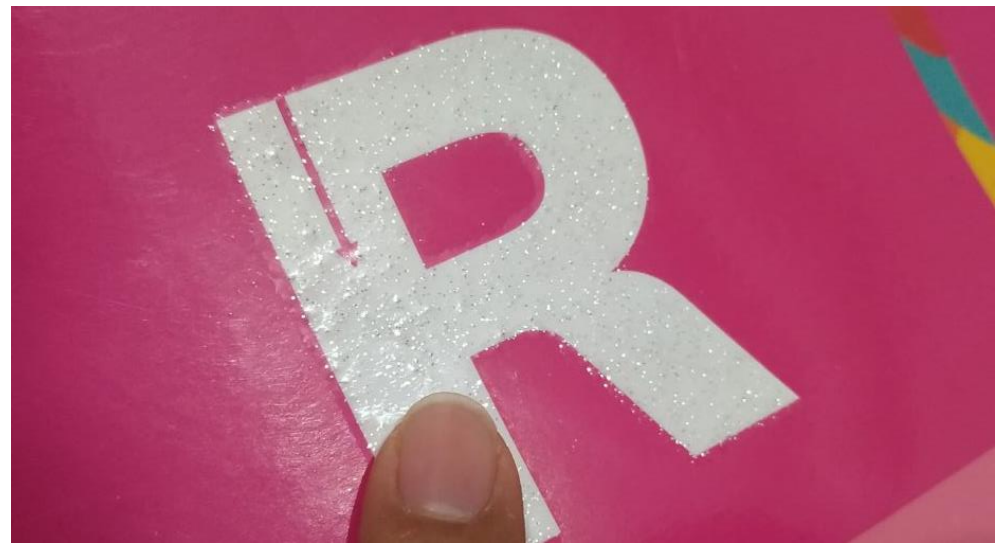

Gambar 15. Penampakan glitter dari dekat Sumber: Rahman, Arumsari dan Azhar, 2019 


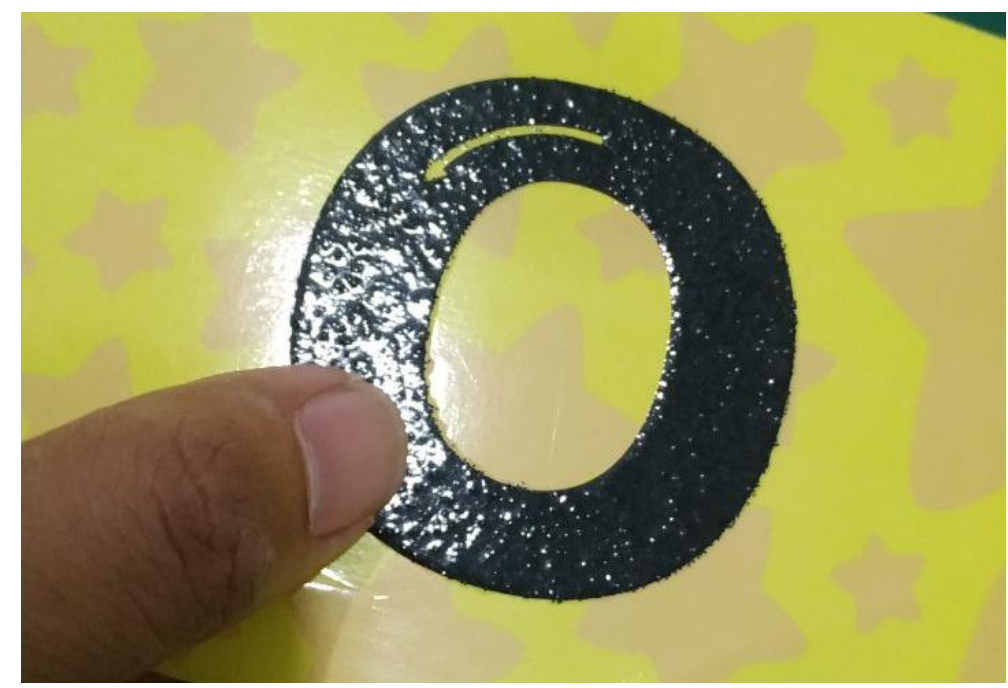

Gambar 16. Glitter mudah diraba dan aman digunakan Sumber: Rahman, Arumsari dan Azhar, 2019

Purwarupa kartu ini memakan biaya cukup besar namun bila diproduksi massal bisa terhitung cukup efisien karena jumlah yang dihasilkan bisa cukup banyak.

Ketiga purwarupa kartu beajar mengenal huruf yang dibuat memiliki beberapa kelebihan dan kelemahan, yang dapat diukur tergantung pada tujuan penggunaannya. Apabila ingin menghasilkan kartu yang berdaya tahan tinggi dan dapat digunakan lama, kartu berbahan dasar impraboard dengan material huruf dari kain flannel bisa menjadi pilihan utama, karena material dasar yang digunakan cenderung awet dan kuat terhadap penggunaan kasar, tidak bisa disobek dan tahan air, sangat sesuai apalagi bila digunakan oleh anak-anak usia dini.

Meski demikian kartu berbahan dasar infraboard dengan material huruf dari pipecleaner tidak terlalu direkomendasikan, karena tidak cukup aman bila digunakan oleh anak-anak. Perlu percobaan lebih lanjut untuk membuat kartu jenis ini bisa menjadi lebih aman untuk digunakan. Sedangkan purwarupa kartu ketiga, yakni yang berbahan kertas dengan laminasi glitter bisa menjadi pilihan utama apabila dilihat dari sisi kemudahan produksi, meski pada tahap praproduksi cukup memakan waktu. 


\section{KESIMPULAN}

Kartu belajar mengenal huruf bisa dibuat dengan menggunakan beragam material selain kertas biasa. Dari tiga alternatif yang diujicoba yaitu flannel, pipe cleaner dan laminasi glitter; kartu dengan menggunakan tekstur dari laminasi berglitter lah yang aman digunakan untuk anak-anak dan mudah diproduksi secara massal. Sebaliknya kartu belajar dengan material flannel maupun pipe cleaner sebetulnya memiliki tekstur yang dapat lebih teraba, namun tidak efisien dari sisi produksi.

Kartu belajar menggunakan kertas dan laminasi berglitter bisa diproduksi secara massal dengan mempertimbangkan beberapa hal, seperti kualitas kertas, kualitas glitter dan standardisasi proses laminasi. Kartu belajar dengan material flannel juga perlu dicarikan solusi agar dapat digunakan dengan lebih aman dan agar dapat diproduksi massal karena memiliki keunggulan dari sisi keterabaan huruf serta kekuatan material.

Penelitian mengenai kartu bertekstur ini berpotensi untuk dilanjutkan terutama dari aspek proses produksi dan ujicoba terhadap responden yang lebih luas. Hal ini juga dapat berlanjut pada penelitian pada aspek bisnis dan komersialisasi. Potensi pada aspek bisnis dan komersialisasi dirasa cukup baik mengingat generasi alfa yang tumbuh di Indonesia cukup banyak dan membutuhkan alat bantu dalam proses belajar. Hal yang bisa menjadi aspek untuk diteliti lebih lanjut adalah kebermanfaatan kartu bertekstur ini sebagai alat bantu pendidikan bagi anak-anak berkebutuhan khusus.

\section{DAFTAR PUSTAKA}

Apriastuti, D.A., 2013. Analisis Tingkat Pendidikan dan Pola Asuh Orang Tua dengan Perkembangan Anak Usia 48-80 Bulan. Bidan Prada: Jurnal IImiah Kebidanan, Vol. 4 No. 1. 
Djiwandono, P.I., 2015. Meneliti itu Tidak Sulit: Metodologi Penelitian Sosial dan Pendidikan Bahasa. Yogyakarta: Deepublish.

Handayani, A., Nurhafizah, 2019. Peningkatan Kemampuan Mengenal Huruf Melalui Permainan Kantong Ajaib di Taman Kanak-Kanak Sadar Bhakti Kecamatan Talamau. Jurnal Riset Tindakan Indonesia, 4 (1), hal. 44-50.

Kertamuda, M.A., 2015. Golden Age: Strategi Sukses Membentuk Karakter Emas pada Anak Sejak Usia Dini. Jakarta: Elex Media Komputindo.

Mais, A., 2018. Media Pembelajaran Anak Berkebutuhan Khusus. Jember: Pustaka Abadi.

Pressman, R.S., 2010. Software Engineering: a practitioner's approach. New York: McGraw-Hill.

Puspitasari, E., 2015. Pengembangan Model Pos PAUD Keliling. EDUCHILD Vol. 4 No. 2, hal 91-96.

Soewardikoen, D.W., 2013. Metodologi Penelitian Visual, Dari Seminar ke Tugas Akhir. Bandung: Dinamika Komunika.

Rahmadani, F., Suryana, D. dan Hartati, S., 2019. Pengaruh Media Sandpaper Letter terhadap Kemampuan Mengenal Huruf Anak di Tk Islam Budi Mulia Padang. Jurnal IImiah Pesona PAUD. Vol 6, No. 1, hal 56 - 67.

Vortuna, D., Ratiyah dan Syafdaningsih, 2018. Peningkatan Kemampuan Mengenal Huruf Melalui Permainan Kartu Huruf pada Kelompok B4 TK Negeri Pembina 1 Palembang Tahun Ajaran 2018/2019. Jurnal Tumbuh Kembang, 5 (2). 